\title{
Impact of Synthetic Clay as Filling Agents on the Dye Adsorption Capacity of Hydrogel
}

\author{
Elvis Fosso-Kankeu*, Frans Waanders, and Johannes Jacobus Venter
}

\begin{abstract}
The focus of this study was to investigate whether the adsorption capacity of a Kappa-carrageenan based hydrogel towards cationic dyes (Basic red and Brilliant green) could be increased by using synthetic clays, cloisite (C) as filling agents. Hydrogel-cloisite composites were synthesized by using a free radical graft copolymerization technique. The hybrid nanocomposites were characterized using SEM and FT-IR spectroscopy. Adsorption experiments investigated the effects of the following parameters: adsorbent dosage, initial dye concentration, and contact time. The Langmuir- and Freundlich isotherm models were used to determine the hydrogel-cloisite nanocomposites adsorption affinity. The firstand second order kinetic models were used to determine the rate of adsorption of cationic dyes. It was found that using cloisite as filling agent for hydrogel resulted in improved adsorption capacity. The hydrogel-cloisite nanocomposite (H-C) displayed the best adsorption capacity for both dyes, with an equilibrium adsorption capacity of $64.14 \mathrm{mg} / \mathrm{g}$ for brilliant green (BG) dye and $58.73 \mathrm{mg} / \mathrm{g}$ for basic red (BR) dye. The nanocomposite saw a $20 \%$ improvement in adsorption capacity towards brilliant green dye and a $17 \%$ improvement towards basic red dye. Kappa-carrageenan hydrogel- clay composites can therefore be considered for the treatment of cationic dye containing wastewater.
\end{abstract}

Keywords - Cationic dyes; Adsorption; Hydrogel; Cloisite; Basic red; Brilliant green.

\section{INTRODUCTION}

Dyes are used in multiple industries to provide color to products from textiles to plastics. Some of these dyes are hazardous and need to be removed from industrial wastewater before it is discharged into the environment. They cause discoloration of water, leaving it aesthetically unpleasing. Colored water also has a negative impact on the environment as the dye could block certain wavelengths of sunlight which is crucial to the survival of aquatic life. [1 - 11] Dyes are relatively stable in water, which means that light, heat and oxidizing agents won't always remove or discolor the dye. [1] Thus a physical separation technique thus needs to be employed.

The main concern with dyes is that they could contain harmful substances like carcinogens and mutagens. [12] This

Elvis Fosso-Kankeu is with the School of Chemical and Minerals Engineering of the North West University, Bult area-Potchefstroom-South Africa.

Frans Waanders is with the School of Chemical and Minerals Engineering of the North West University, Bult area-Potchefstroom-South Africa

Johannes Jacobus Venter is with the School of Chemical and Minerals Engineering of the North West University, Bult area-Potchefstroom-South Africa. would render the industrial waste water as toxic. This water thus has to be treated in order to correct the color and reduce the toxic effects. As clean water is becoming of ever growing importance there are numerous techniques available to treat industrial wastewater, each with their own limitations [13 17]. These techniques include: chemical degradation, adsorption, precipitation, biodegradation and chemical coagulation [18]. Biological methods require a lot of time and aren't very effective against synthetic polymer dyes. Chemical coagulation generates large amounts of sludge, which means it essentially trades one type of pollution for another. [19] Considers chemical degradation with chlorine to be highly effective, although it leads to the production of organochlorine compounds which are highly toxic. Ultrasonic and UV-ozone oxidation are also available, but not yet economically feasible [12]

Adsorption on the other hand is more favorable for water treatment since it is cost effective and has a small impact on the environment, especially when natural adsorbents like clays are used [20 - 25].

Hydrogel refers to a group of polymers in a threedimensional network which is able to absorb large amounts of water (much like clay) without dissolving because they possess cross-linked polymer chains that are hydrophilic [26]. Hydrogels are used as adsorbents because they have certain functional groups $\left(\mathrm{OH}, \mathrm{NH}_{2}, \mathrm{SO}_{3} \mathrm{H}, \mathrm{COOH}, \mathrm{COHN}_{2}\right)$ which are able to remove aqueous pollutants with electrostatic interactions [26]. Although hydrogel is effective at adsorbent there are still concerns with its stability and reusability. [27] Polysaccharide based hydrogels are low cost, biocompatible and biodegradable, which makes it the ideal candidate to use as adsorbent [28].

"Clays are hydrous aluminosilicates broadly defined as those minerals that make up the colloid fraction of soils, sediments, rocks and water and may be composed of mixtures of fine grained clay minerals and clay sized crystals of other minerals such as quartz carbonate and metal oxides" [29 - 34]. Clays contain organized layered structures whereby they are grouped and they have a large water retention capacity. [29] Clay has the advantage of being a nanoparticle, this results in increased surface area and it increases the ability for surface ion exchange, which makes clay ideal for use in adsorption.[9] An approach that has shown improved adsorption capacities, is to enrich hydrogel polymers with clay to make a composite material. [20] The polymer composite material is expected to have much better adsorption capacities. Since the clay and hydrogel have similar properties that can be combined in order to complement each other [20]. 
In this study, the focus is to investigate the adsorption efficiency of a Polysaccharide based hydrogel when filled with synthetic clay.

\section{II.EXPERIMENTAL}

\section{A. Materials}

The following chemicals were used during experimentation: Acrylamide "AA" (Sigma Aldrich), N,NMethylenebisacrylamide "MBA" (Sigma Aldrich), KCarrageenan (Sigma Aldrich), Basic red cationic dye (Sigma Aldrich), Basic brilliant green cationic dye (Sigma Aldrich), Potassium persulfate "KPS" (Sigma Aldrich), Cloisite-20 was kindly offer by BYK-Chemie $\mathrm{GmbH}$ from Germany and Bentonite clay were obtained from the NWU School of Chemical and Minerals Engineering's storage facilities and had a particle size of $106 \mu \mathrm{m}$ and smaller

\section{B. Preparation of Hydrogel and Nanocomposites}

The adsorbents were synthesized using a free-radical graft co-polymerization technique. $1 \mathrm{~g}$ of K-Carrageenan was added to $50 \mathrm{~mL}$ of deionized water in a $250-\mathrm{mL}$ beaker and stirred with a magnetic bar for 10 minutes until completely mixed. 40 $\mathrm{mg}$ of KPs (initiator) was added to the solution and stirred for 5 minutes. Followed by the addition of $60 \mathrm{mg}$ of MBA (Cross linker) and stirred for another 5 minutes. Finally, $1 \mathrm{~g}$ AA (monomer) was added to the mixture and it was stirred again for 5 minutes.

The beaker was placed inside an incubator, at $45^{\circ} \mathrm{C}$, to allow the reaction to continue for 24 hours.

The newly synthesized hydrogel was then allowed to cool to room temperature and cut into $5 \mathrm{~mm}$ by $5 \mathrm{~mm}$ cubes. The hydrogel cubes were submerged in deionized water in order to dissolve and remove homopolymer and unreacted monomers. The water was replaced every 24 hours for 7 days.

Finally, the hydrogel was dried in a hot air oven for 24 hours at $60{ }^{\circ} \mathrm{C}$. The hydrogel was then crushed with a mortar and pestle and sieved to 106 micrometers.

For preparation of the Hydrogel-Cloisite nanocomposites, the aforementioned procedure was followed, with the exception that $2 \mathrm{wt} \%$ cloisite was added to the mixture directly after adding K-Carrageenan.

\section{Characterization of the Adsorbents}

Characterization of the hydrogel $(\mathrm{H})$, and hydrogel-cloisite nanocomposite $(\mathrm{H}-\mathrm{C})$ was done with an FT-IR spectrometer. Functional groups in the adsorbents were identified to evaluate the surface activation. The FT-IR spectrometry was done by using a IRAffinity-1S Fourier transform infrared spectrophotometer from Shimadzu with a spectral range from $4000-500 \mathrm{~cm}^{-1}$.

\section{Adsorption Studies}

The equilibrium concentration of the dye solutions after adsorption was determined with a Genesys 10S UV-Vis spectrophotometer at the following optimal wavelengths: $426.5 \mathrm{~nm}$ for brilliant green dye and $290 \mathrm{~nm}$ for the basic red dye.
Batch adsorption experimentation was carried out, the shaking incubator was set at a constant rotational speed of $160 \mathrm{rpm}$, the solution volume was kept constant at $0.1 \mathrm{~L}$ and temperature was kept at $25^{\circ} \mathrm{C}$. The influence of the following parameters was investigated: adsorbent dosage $(10-100 \mathrm{mg})$, contact time (10-145 $\mathrm{min})$ and initial dye concentration (10-80 mg/L).

\section{E. Isotherm and Kinetic Models}

The adsorption affinity of $\mathrm{H}, \mathrm{H}-\mathrm{C}$ and $\mathrm{H}-\mathrm{B}$ for the removal of brilliant green and basic red cationic dyes was evaluated by fitting Freundlich and Langmuir isotherms to the data. [35, 36]. The Langmuir isotherm model assumes that adsorption occurs in a monolayer about the adsorbent and is typically used with single solute systems. The linearized form of the Langmuir equation is given as follows: [37]

$\frac{C_{e}}{q_{e}}=\frac{1}{k \cdot q_{m}}+\frac{C_{e}}{q_{m}}$

The Freundlich model however, does not have any monolayer restrictions and can be applied to heterogeneous systems. The linearized form of the Freundlich equation is given as:[37]

$\log q_{e}=\log k_{f}+\frac{1}{n} \cdot \log C_{e}$

Where: $C_{e}=$ the concentration of dye at equilibrium in $[\mathrm{mg} / \mathrm{L}]$,

$q_{e}=$ the equilibrium adsorption capacity in $[\mathrm{mg} / \mathrm{g}]$

$q_{m}=$ Maximum adsorption capacity $[\mathrm{mg} / \mathrm{g}]$

$\mathrm{k}=$ the Langmuir constant related to energy released during adsorption $[\mathrm{L} / \mathrm{mg}]$

$k_{f}=$ the Freundlich adsorption capacity parameter in $(\mathrm{mg} / \mathrm{g})$ and

$n=$ the intensity of adsorption.

Pseudo first- and second order models were fitted to the adsorption rate data in order to assist with the determination of the adsorption rate [36]. The linearized pseudo first-order model is given by:

$$
\log \left(q_{e}-q_{t}\right)=\log q_{e}-k_{1} \cdot \frac{t}{2.303}
$$

And the linearized pseudo second-order model is given by:

$$
\frac{t}{q_{t}}=\frac{1}{k_{2} q_{e}^{2}}+\frac{1}{q_{e}} \cdot t
$$

where: $q_{e}=$ the equilibrium adsorption capacity in $[\mathrm{mg} / \mathrm{g}]$

$$
\mathrm{q}_{\mathrm{t}}=\text { the adsorption capacity at time } \mathrm{t} \text { in }[\mathrm{mg} / \mathrm{g}] \text {, }
$$

$k_{1}=$ the first order rate constant in $\left[\mathrm{min}^{-1}\right]$,

$k_{2}=$ the second order rate constant in $\left[\mathrm{g} / \mathrm{mg} \cdot \mathrm{min}^{-1}\right]$,

$t=$ the time in [min].

\section{RESULTS AND DISCUSSION}

\section{A. FT-IR Analyses}

The FT-IR results of the synthesized H, H-C composite and $\mathrm{C}$ before adsorption can be seen in Fig1. 


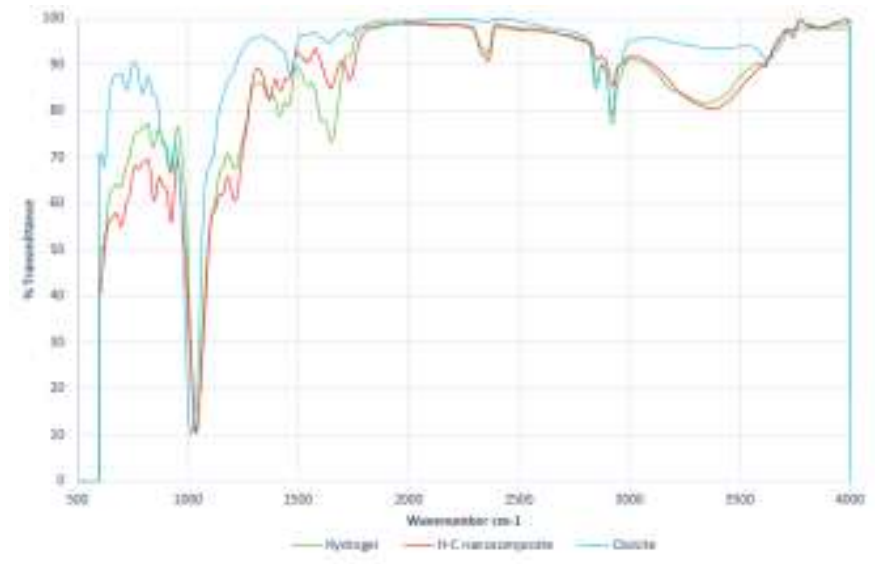

Fig. 2: FT-IR spectra of (a) Hydrogel, (b) Cloisite and (c) H-C nanocomposite

From this figure it is evident that noticeable differences are present in the IR-spectra of $\mathrm{H}$ and $\mathrm{H}-\mathrm{C}$ due to the cloisite influencing the structure of the hydrogel.

As is characteristic of kappa-carrageenan a strong adsorption band is present at about $843 \mathrm{~cm}^{-1}$, which is due to $\mathrm{C}-\mathrm{O}-\mathrm{SO}_{3}$ bond of D-galactose-4-sulphate (G4S). [29]

Another strong band is visible at approximately $928 \mathrm{~cm}^{-1}$ (between 925 and $935 \mathrm{~cm}^{-1}$ ) in the FTIR- spectra, which is characteristic of $\mathrm{C}-\mathrm{O}$ bonds present in 3,6-anhydro-Dgalactose (DA), another main constituent of KappaCarrageenan [29]

Another strong peak in adsorption occurs at $1038 \mathrm{~cm}^{-1}$ due to stretching vibration of its $\mathrm{C}-\mathrm{OH}$ group and another absorption band at $1215 \mathrm{~cm}^{-1}$ indicates the presence of sulfate esters $(\mathrm{S}=\mathrm{O})$. The adsorption band at $1649 \mathrm{~cm}^{-1}$ is due to $\mathrm{C}=\mathrm{O}$ stretch vibrations, indicating the presence of ketones of varying intensity in all three samples

The broad adsorption peaks between 3200 and $3600 \mathrm{~cm}^{-1}$ are due to stretching vibrations of the hydrogen bonded $\mathrm{O}-\mathrm{H}$ and $\mathrm{COOH}$-groups present in the hydrogel, cloisite and $\mathrm{H}-\mathrm{C}$ composite. There is a $50 \mathrm{~cm}^{-1}$ shift rightwards in the adsorption band of the $\mathrm{H}-\mathrm{C}$ composite when compared to the peak of $\mathrm{H}$. The $\mathrm{H}-\mathrm{C}$ peak also has a $3 \%$ increase in absorbance in this region, indicating that the cloisite filling altered the structure of the Hydrogel.

In the region $2915-2850 \mathrm{~cm}^{-1}$, two strong peaks are present in the Hydrogel and cloisite samples, these peaks indicate a symmetric and asymmetric stretching vibration of $(\mathrm{C}-\mathrm{H})$ methyl groups that appear to have shifted upward and slightly to the right in the $\mathrm{C}-\mathrm{H}$ composite. This is due to $-\mathrm{CH}_{3}$ groups interposition in the two molecules

Increasing peak intensities in the region of 1450 and 1500 indicate the presence of secondary amine $(\mathrm{N}-\mathrm{H})$ bending vibrations in the $\mathrm{H}-\mathrm{C}$ composite. Secondary amines are also present in pure hydrogel's structure, before filling with cloisite. However, there is a reduction in the intensity of these peaks, coupled with a leftwards shift confirm that the hydrogel was indeed modified.

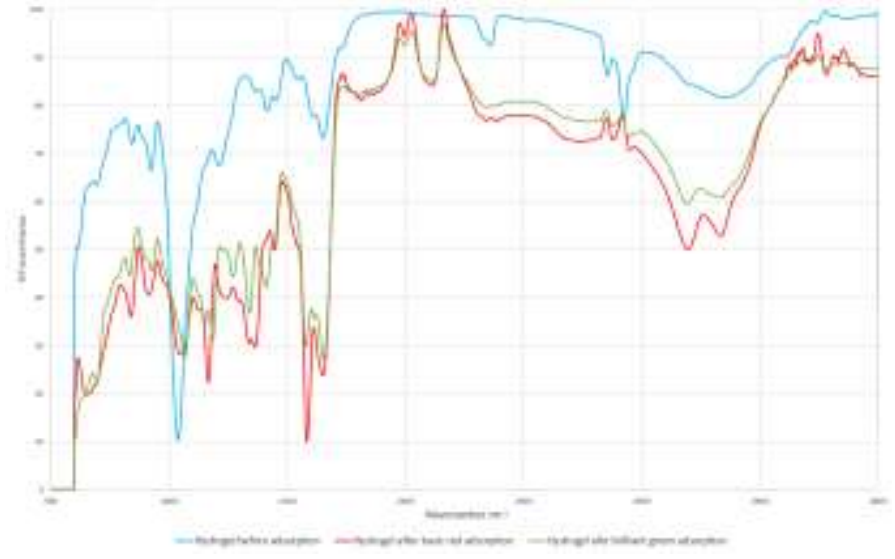

Fig. 3: FT-IR spectra of (a) Hydrogel and of Hydrogel after the adsorption of (b) BR and (c) BG

Fig. 3 illustrates the FT-IR spectra after basic red and brilliant green adsorption on pure hydrogel. It appears that hydrogel has a higher adsorption affinity towards the basic red dye, as the transmittance bands are experiencing taller peaks than those present in hydrogel after brilliant green adsorption, especially at the Ketone stretch region between 1625 and 1750 $\mathrm{cm}^{-1}$. Hydrogel experienced a ketone stretch at $1700 \mathrm{~cm}^{-1}$, which was shifted left and substantially increased in intensity after dye adsorption. The asymmetric stretching vibrations of carboxyl $(\mathrm{COOH})$ and hydroxyl $(\mathrm{O}-\mathrm{H})$ groups can be seen between $3200-3600 \mathrm{~cm}^{-1}$. Another significant peak can be seen at $3250 \mathrm{~cm}^{-1}$, this peak isn't present in the pure hydrogel and is thus the result of hydrogen bonds between the dye and the hydrogel.

The H-C composites FT-IR spectra has almost the same peaks as the hydrogel after adsorption of dyes, with the main distinctions between them being the increase in the intensity of the adsorption bands found in H-C composite after dye adsorption. The clay filled hydrogel appears to have a greater adsorption affinity for the brilliant green dye.

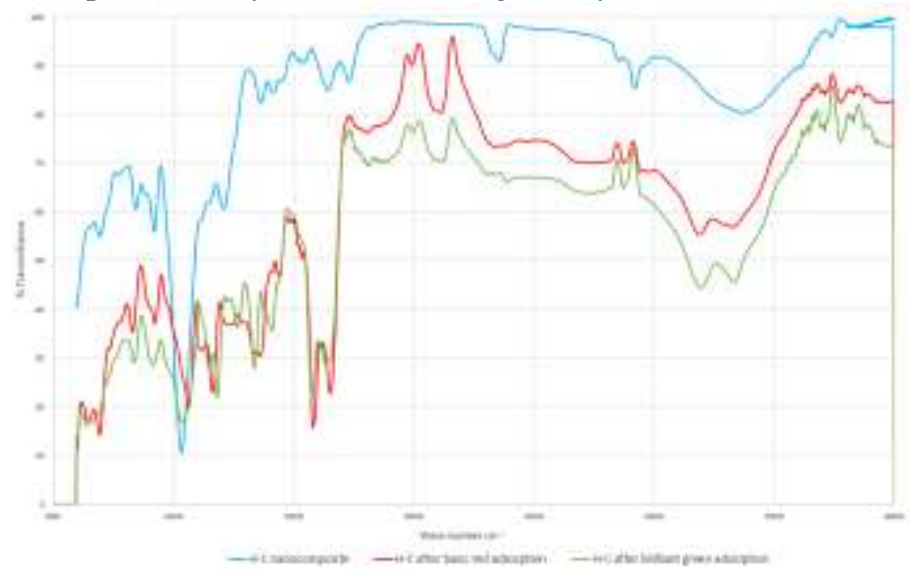

Fig.4: FT-IR spectra of (a) H-C nanocomposite and of $\mathrm{H}$ nanocomposite after the adsorption of (b) BR and (c) BG

\section{B. Adsorption Behavior}

The effect of adsorbent dosage of Hydrogel and $\mathrm{H}-\mathrm{C}$ composite is investigated in Fig. 5 below. The following 
conditions were used: Initial dye concentration of dyes was kept constant at $50 \mathrm{mg} / \mathrm{L}$, contact time was kept constant at $150 \mathrm{~min}$, a temperature of $25^{\circ} \mathrm{C}$ was used and the mixture was stirred at 160rpm. Adsorbent dosages of 20, 40, 60, 80 and $100 \mathrm{mg}$ were investigated. The optimum adsorbent dosage for $\mathrm{BR}$ and $\mathrm{BG}$ dyes was determined as $80 \mathrm{mg}$ for all 3 adsorbents, and was used in further adsorption experiments. Too much or too little adsorbents resulted in fewer dye being removed. It was also observed that the hydrogel clay composites and the pure hydrogel appeared to favor the BG dye as it's removal efficiency was consistently the largest.

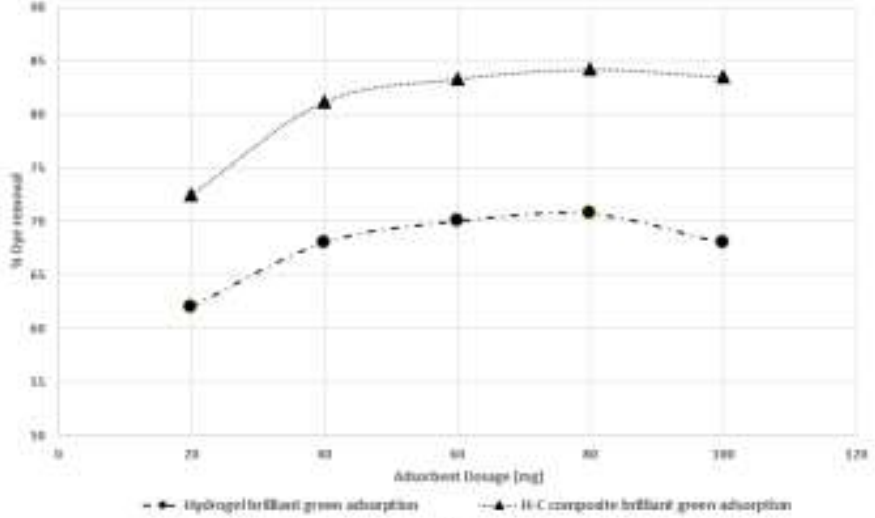

Fig. 5: Effect of adsorbent dosage on the adsorption of dye for a contact time of $150 \mathrm{~min}$

The optimum contact time of the adsorption of cationic dyes, BR and BG, was determined to be 115 min for all 3 adsorbents. The adsorption experiments were done with the optimal absorbent dosage of $80 \mathrm{mg}$, an initial dye concentration of $50 \mathrm{mg} / \mathrm{L}$ investigated at the optimum adsorbent dosage and at a concentration of $50 \mathrm{mg} / \mathrm{L}$. At a temperature of $25^{\circ} \mathrm{C}$ and a rotational speed of $160 \mathrm{rpm}$, it was found that the adsorption capacity of the adsorbent increased rapidly until $70 \mathrm{~min}$ and then increased slowly until it reached equilibrium at $115 \mathrm{~min}$. This is due to the limited number of active sites available on the adsorbent. The $\mathrm{H}-\mathrm{C}$ composite achieved the best adsorption capacity of $52.64 \mathrm{mg} / \mathrm{g}$ for BG vs the $44.19 \mathrm{mg} / \mathrm{g}$ achieved with Hydrogel.

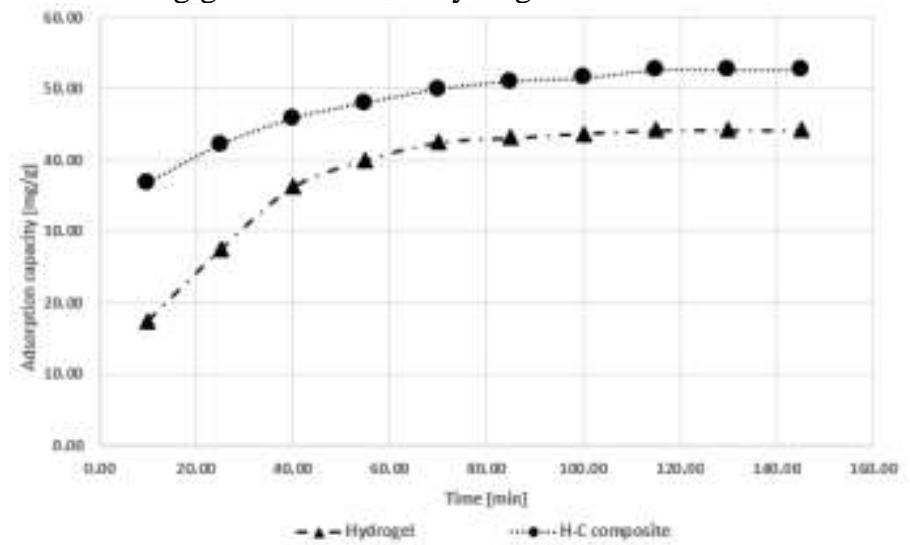

Fig 6: Effect of time on Brilliant green dye adsorption

The optimal initial dye concentration, as seen in Fig. 6, was determined at the optimal adsorbent dosage and contact time, while keeping temperature constant at $25^{\circ} \mathrm{C}$ and the shaking incubator at $160 \mathrm{rpm}$. Dye concentrations of 10, 20, 30, 40, 50,
60, 70 and 80 were investigated. Adsorption capacity of all 2 adsorbents increased rapidly until an initial dye concentration of approximately $60 \mathrm{mg} / \mathrm{L}$ was reached. After which the adsorption capacity seemed to decline slightly. The optimal initial dye concentration was determined as $60 \mathrm{mg} / \mathrm{L}$ for BG dye and $70 \mathrm{mg} / \mathrm{L}$ for BR dye. This could be due to the brilliant green dye having a larger adsorption affinity towards these adsorbents. Again the $\mathrm{H}-\mathrm{C}$ composite achieved the best adsorption capacity at $65.15 \mathrm{mg} / \mathrm{g}$ and the pure hydrogel performed the worst with $53.05 \mathrm{mg} / \mathrm{g}$.



Fig 7: Effect of initial dye concentration on Brilliant green dye adsorption

\section{C.Isotherm Model Results}

A linearized Langmuir isotherm was plotted for the adsorption of $\mathrm{BG}$ dye by means of hydrogel and $\mathrm{H}-\mathrm{C}$ composite (Fig.9). From the isotherms, trend lines were fitted and their coefficient of determination $\left(\mathrm{R}^{2}\right)$ was calculated, along with the constants of the Langmuir model. As the $\mathrm{R}^{2}$ $>0.98$ the Langmuir model can be seen as a good fit for the collected data.

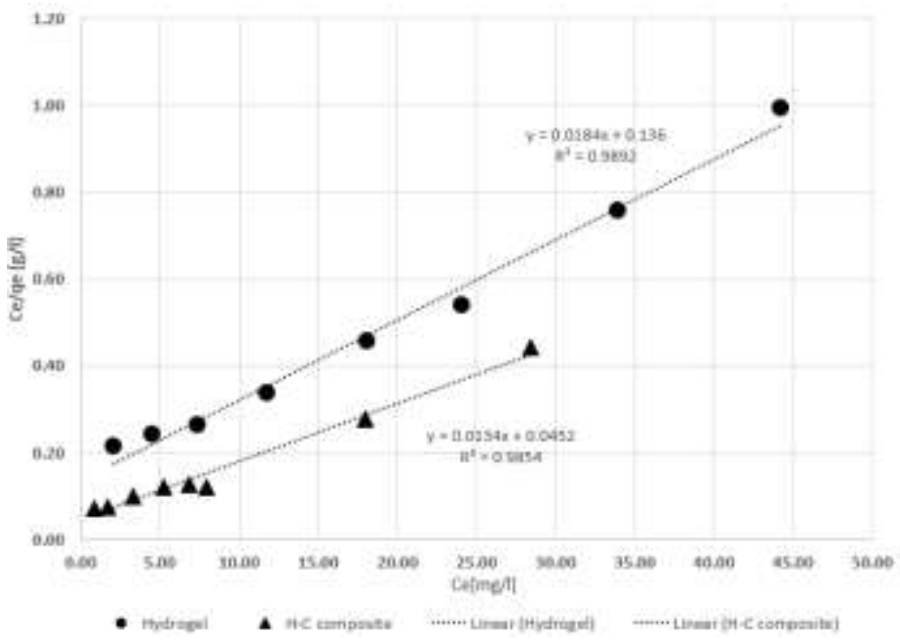

Fig 8: Linear regression of the Langmuir isotherm model

The Freundlich isotherm model was also fitted to the adsorption data, as can be seen in Fig.10. However, Table 1 shows that the calculated $\mathrm{R}^{2}$ values are $<0.98$, meaning the Freundlich model cannot be seen as the best fit for the adsorption data. The Langmuir model is therefore suitable to 
predict the adsorption; implying that the BG dye is adsorbed onto the adsorbents by binding onto a monolayer surface.

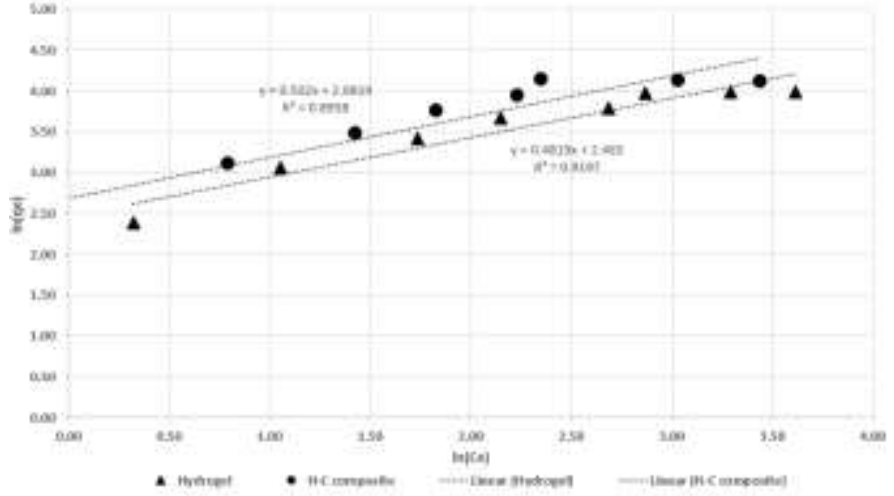

Fig. 9: Linear regression of the Freundlich isotherm mode

TABLE I

CONSTANTS FOR THE ISOTHERMAL

Models

\begin{tabular}{|c|c|c|c|c|}
\hline & \multicolumn{2}{|c|}{ Langmuir isotherm } & \multicolumn{2}{|c|}{ Freundlich isotherm } \\
\hline & Hydrogel & H-C composite & Hydrogel & H-C composite \\
\hline $\mathbf{R}^{2}$ & 0.989 & 0.985 & 0.920 & 0.896 \\
\hline$q_{m}[m g / g]$ & 63.89 & 74.493 & - & $\cdot$ \\
\hline k [L/mg] & 0.002 & 0.001 & - & - \\
\hline n & - & - & 2.075 & 2.024 \\
\hline kf [mg/g] & - & - & 11.763 & 14.613 \\
\hline
\end{tabular}

Adsorption experimental data by plotting a graph of $\log \left(\mathrm{q}_{\mathrm{e}^{-}}\right.$ $\mathrm{q}_{\mathrm{t}}$ ) as a function of time (see Fig. 11). While for the pseudo second-order kinetic model, a graph of $\mathrm{t} / \mathrm{q}_{\mathrm{t}}$ as a function of time was plotted [38] (Fig.12). The calculated $R^{2}$ values and kinetic model constants can be seen in Table 2. The large $\mathrm{R}^{2}$ values indicate that both kinetic models are good fits for the adsorption data in question [39]. With the pseudo second order kinetic model providing a slightly better fit to the data. Adsorption rate constants can be seen in Table II.

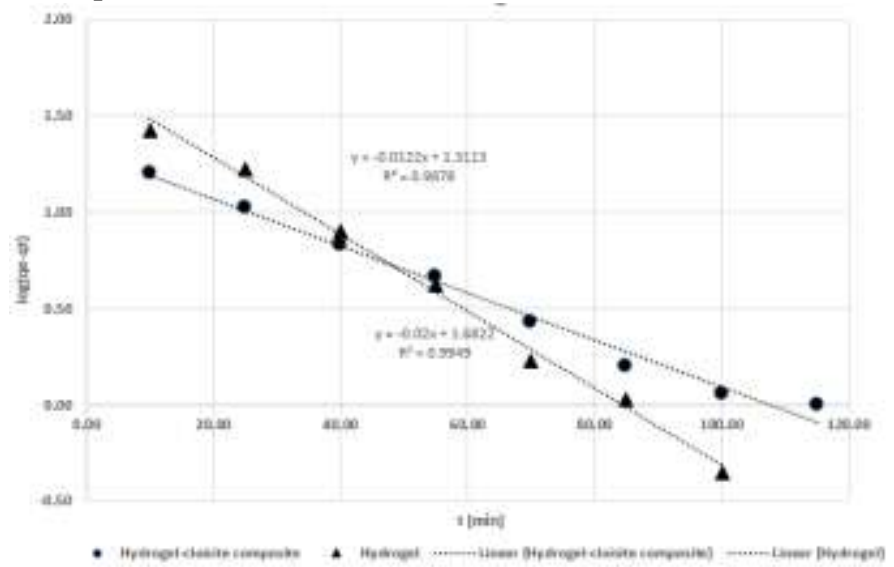

Fig 11: Linear regression of pseudo first order kinetics

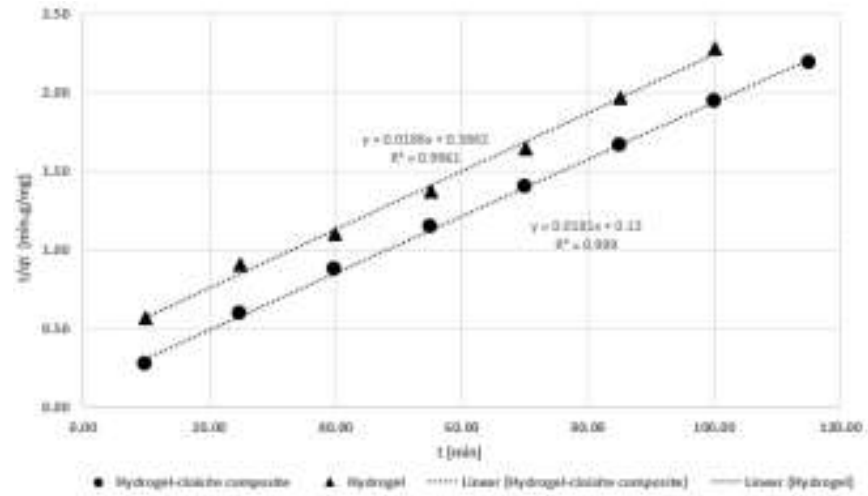

Fig 12: Linear regression of pseudo second order kinetic model

TABLE II CONSTANTS FOR THE PSEUDO FIRST- AND SECOND ORDER KINETIC MODELS

\begin{tabular}{|l|c|c|c|c|}
\hline \hline & \multicolumn{2}{|c|}{ Pseudo 1st order } & \multicolumn{2}{c|}{ Pseudo 2nd order } \\
\hline & Hydrogel & H-C composite & Hydrogel & H-C composite \\
\hline $\mathbf{R}^{2}$ & 0.988 & 0.995 & 0.996 & 0.999 \\
\hline $\mathbf{q}_{\mathrm{e}}[\mathrm{mg} / \mathrm{g}]$ & 39.830 & 44.193 & 50.340 & 55.371 \\
\hline $\mathbf{k}_{1}\left[\mathrm{~min}^{-1}\right]$ & 0.027 & 0.022 & - & - \\
\hline $\mathbf{k}_{2}[\mathrm{~g} / \mathrm{mg} \cdot \mathrm{min}-1]$ & - & - & 0.001 & 0.003 \\
\hline \hline
\end{tabular}

The $\mathrm{R}^{2}$ values in Table II indicate that the experimental data can be represented by both the pseudo-first and pseudosecond order model as the $\mathrm{R}^{2}$ values are both larger than 0.98.The modelled adsorption capacity of hydrogel and H-C composite are $50.34 \mathrm{mg} / \mathrm{g}$ and $55.37 \mathrm{mg} / \mathrm{g}$ as predicted by the pseudo-second order model (chemisorption mechanism) and $39.83 \mathrm{mg} / \mathrm{g}$ and $44.19 \mathrm{mg} / \mathrm{g}$ as predicted by the pseudo-first order model (physisorption mechanism), respectively, for brilliant green dye.

The results obtained in Table II clearly indicate that hydrogel and $\mathrm{H}-\mathrm{C}$ composite are capable of quickly removing cationic dye from wastewater and that clay composites provide enhanced adsorption with synthetic clay offering the best improvements. This indicates successful synthesis of a hydrogel-clay nanocomposite. Similar results were obtained in previous studies $[36,38]$.

\section{CONCLUSION}

From the characterization of adsorbents, it can be seen that hydrogel and H-C composite were synthesized successfully. From the adsorption experiments it can be concluded that using clay as a filling agent, delivers substantial improvements in the adsorbents adsorption capacity. The nanocomposite performed more than $20 \%$ better than the normal hydrogel. The results obtained throughout this study revealed that cloisite filled Hydrogel nanocomposite consistently showed superior adsorption capacities and affinity towards the BG cationic dye. The adsorption data were found to best fit the pseudo-second order kinetic model, implying that the adsorption of BG dye mainly occurred through a chemisorption mechanism. The filling of hydrogel with clay could therefore be considered as possible solution for the development of smart adsorbent for the removal of cationic dye from solution. 
From the Isotherm data, the Langmuir model had the best fit, thus it can be concluded that most of the adsorption occurs on a single layer on the adsorbent material.

The batch kinetic studies revealed that the adsorption data corresponded excellently with pseudo first order and pseudo second-order kinetic models. Thus, both chemisorption and physisorption are taking place.

From the results obtained it can be concluded that hydrogel cloisite nanocomposite is the most effective adsorbent in the removal of $\mathrm{BG}$ and $\mathrm{BR}$ dyes from solution. It has an adsorption capacity of $64.14 \mathrm{mg} / \mathrm{g}$ for BG and $58.73 \mathrm{mg} / \mathrm{g}$ for BR. H-C composite can therefore be used for the removal of cationic dyes.

\section{ACKNOWLEDGMENT}

The authors are grateful to the sponsor from the North-West University and the National Research Foundation in South Africa. Any opinion, findings and conclusions or recommendations expressed in this material are those of the authors and therefore the NRF does not accept any liability in regard thereto. The authors appreciate the contribution of $\mathrm{Mr}$ E. Malenga and Ms N. Baloyi from the University of Johannesburg in South Africa; Mr N. Lemmer from the NorthWest University.

\section{REFERENCES}

[1] Kono, H., 2015. Preparation and charecterization of amphoteric cellulose hydrogels as adsorbents for the anionic dyes inaqueous solutions. Gels, Volume 1, pp. 94-116.

[2] E. Fosso-Kankeu, F. Waanders, C.L. Fourie. 2016. Adsorption of Congo Red by surfactant-impregnated bentonite clay. Desalination and Water Treatment. doi: 10.1080/19443994.2016.1177599: 1-9.

[3] E Fosso-Kankeu, A Webster, IO Ntwampe, FB Waanders. 2016. Coagulation/flocculation potential of polyaluminium chloride and bentonite clay tested in the removal of methyl red and crystal violet. Arabian Journal for Science and Engineering. DOI 10.1007/s13369016-2244-x.

[4] Elvis Fosso-Kankeu, Frans Waanders, Maryka Geldenhuys. 2016. Impact of nanoparticles shape and dye property on the photocatalytic degradation activity of $\mathrm{TiO} 2$. International Journal of Science and Research. 5 (11): 528 - 535.

[5] Elvis Fosso-Kankeu, Lwandle Simelane (2013): Kinetic study of methylene blue removal by Gram-negative and Gram-positive bacteria. International Multi-conference on Education, Law, Environment and Metallurgical Engineering (IMELEME' 2013); 27-28 November 2013, Johannesburg-South Africa. (Award Winning Paper). Editors: Sandhu S and Muzenda E. ISBN: 978-93-82242-50-5.

[6] Elvis Fosso-Kankeu, Frans Waanders, Corinne Fraser. 2014. Bentonite clay adsorption affinity for anionic and cationic dyes. $6^{\text {th }}$ International Conference on Green Technology, Renewable Energy and Environmental Engineering (ICGTREEE'2014). 27-28 November 2014, Cape Town-South Africa. Editors: Muzenda E. and Sandhu S. ISBN: 978-93-84468-08-8. Pp 257-260. Pp 257-260.

[7] Elvis Fosso-Kankeu; Oupa Ntwampe; Frans Waanders, and Alicea Webster. 2015. The Performance of Polyaluminium Chloride and Bentonite clay Coagulant in the Removal of Cationic and Anionic Dyes. $7^{\text {th }}$ International Conference on Latest Trends in Engineering and Technology (ICLTET' 2015), November 26-27, 2015 Irene, Pretoria (South Africa). Editors: E. Muzenda and T Yingthawornsuk. ISBN: 978-93-84422-58-5.

[8] Elvis Fosso-Kankeu, Frans Waanders, and Charissa Laurette Fourie. 2015. Surfactant Impregnated Bentonite Clay for the Adsorption of Anionic Dyes. $7^{\text {th }}$ International Conference on Latest Trends in Engineering and Technology (ICLTET' 2015), November 26-27, 2015
Irene, Pretoria (South Africa). Editors: E. Muzenda and T Yingthawornsuk. ISBN: 978-93-84422-58-5.

[9] Elvis Fosso-Kankeu, Frans Waanders, and Maryka Geldenhuys. 2015. Photocatalytic Degradation of Dyes using $\mathrm{TiO}_{2}$ Nanoparticles of Different Shapes. $7^{\text {th }}$ International Conference on Latest Trends in Engineering and Technology (ICLTET' 2015), November 26-27, 2015 Irene, Pretoria (South Africa). Award Winning Paper. Editors: E. Muzenda and T Yingthawornsuk. ISBN: 978-93-84422-58-5.

[10] Fosso-Kankeu E, Waanders F, Potgieter J. 2016. Enhanced adsorption capacity of sweet sorghum derived biochar towards malachite green dye using bentonite clay. International Conference on Advances in Science, Engineering, Technology and Natural Resources (ICASETNR-16) Nov. 24-25, 2016, Parys - South Africa. ISBN: 978-93-84468-79-8.

[11] Fosso-Kankeu E, Waanders F, Taljaard L. 2016. Effect of oxidants on the photocatalytic degradation of methylene blue and congo red under sunlight. International Conference on Advances in Science, Engineering, Technology and Natural Resources (ICASETNR-16) Nov. 24-25, 2016, Parys - South Africa. ISBN: 978-93-84468-79-8.

[12] Daneshvar, N., Oladegaragoze, A. \& Djafardazeh, N., 2006. Decolorization of basic dye solution by electrocoagulation: an investigation of the effect of operational parameters. Hazard Mater, Volume 129, pp. 116-122.

[13] Fosso-Kankeu E, Mulaba-Bafubiandi A, Mamba BB, Barnard TG. 2009. Mitigation of $\mathrm{Ca}, \mathrm{Fe}$, and $\mathrm{Mg}$ loads in surface waters around mining areas using indigenous microorganism strains. Journal of Physics and Chemistry of the Earth, Vol 34, pp 825-829.

[14] Fosso-Kankeu E, Mulaba-Bafubiandi A, Mamba BB, Marjanovic L, Barnard TG. 2010. A comprehensive study of physical and physiological parameters that affect biosorption of metal pollutants from aqueous solutions. Journal of Physics and Chemistry of the Earth, Vol 35 , pp 672-678.

[15] E. Fosso-Kankeu, AF Mulaba-Bafubiandi, BB Mamba and TG Barnard. 2011. Prediction of metal-adsorption behaviour in the remediation of water contamination using indigenous microorganisms. Journal of Environmental Management, 92 (10), pp 2786-2793.

[16] H. Mittal, E. Fosso-Kankeu, Shivani B. Mishra, Ajay K. Mishra. 2013. Biosorption potential of Gum ghatti-g-poly (acrylic acid) and susceptibility to biodegradation by B. subtilis. International Journal of Biological Macromolecules. 62: 370-378.

[17] E. Fosso-Kankeu, AF Mulaba-Bafubiandi. 2014. Challenges in the escalation of metal-biosorbing processes for water treatment: applied and commercialized technologies. African Journal of Biotechnology. 13(17): 1756-1771.

[18] Pajootan, E. A. ,. M. M. N., 2012. Binary system dye removal by electrocoagulation from synthetic and real colored wastewaters. Journal of Taiwan Institute of chemical engineering, Volume 63, pp. 282-290.

[19] Merzouk, B., Yakoubi, M. \& Zongo, L., 2011. Effect of modification of textile wastewater composition on electrocoagulation efficiency. Desalination, Volume 275, pp. 181-86.

[20] Ali, L., Asim, M., AM \& Khan, 2012. Low cost adsorbents for the removal of organic polutants from wastewater. Environ. Manag., Volume 113, pp. 170-183.

[21] E. Fosso-Kankeu, H. Mittal, F. Waanders, I.O. Ntwampe, S.S. Ray. 2016. Preparation and characterization of gum karaya hydrogel nanocomposite flocculant for metal ions removal from mine effluents. International Journal of Environmental Science and Technology. 13: 711-724.

[22] E. Fosso-Kankeu, F. Waanders, E. Maloy. 2016. Copolymerization of ethyl acrylate onto guar gum for the adsorption of $\mathrm{Mg}$ (II) and $\mathrm{Ca}$ (II) ions. Desalination and Water Treatment. doi: 10.1080/19443994.2016.1165147: 1-10.

[23] E. Fosso-Kankeu, A.F. Mulaba-Bafubiandi, L.A. Piater, M.G. Tlou. 2016. Cloning of the cnr operon into a strain of Bacillaceae bacterium for the development of a suitable biosorbent. World Journal of Microbiology and Biotechnology. DOI 10.1007/s11274-016-2069-5.

[24] Elvis Fosso-Kankeu, Hemant Mittal, Frans Waanders, Suprakas Sinha Ray. 2017. Thermodynamic properties and adsorption behaviour of hydrogel nanocomposites for cadmium removal from mine effluents. Journal of Industrial and Engineering Chemistry. 48: 151-161.

[25] Elvis Fosso-Kankeu, Frans B. Waanders, Frederik W. Steyn. 2017. Removal of $\mathrm{Cr}(\mathrm{VI})$ and $\mathrm{Zn}$ (II) from an aqueous solution using an 
organic-inorganic composite of bentonite-biochar-hematite. Desalination and Water Treatment. 59: 144-153.

[26] Schacht, E., 2004. Polymer chemistry and hydrogel systems. Serbia, Phys conf. Ser J.

[27] Ozay, O. et al., 2010. Utilization of magnetic hydrogels in seperation of Toxic metal ions from aqueous environments. Desalination, Volume 260, pp. 1-3; 57-64.

[28] Crini, G., 2006. Non conventional, low cost adsorbents for dye removal : a review. Bioresource technology, Volume 97, pp. 1061-1085.

[29] Pinnavaia, T., 1983. Intercalated clay catalysts. J. Sci., 220(4595), pp. 365-371.

[30] E. Fosso-Kankeu, Hemant Mittal, S. Marx and Suprakas Sinha Ray. 2016. Hydrogel-based bioflocculants for the removal of organic pollutants from biodiesel wastewater. Journal of Polymer and Environment. DOI 10.1007/s10924-016-0870-8.

[31] E. Fosso-Kankeu, F. Waanders. 2014. Metal Ions Adsorption Affinity of Clay Materials from the North West Province of South Africa. An Interdisciplinary Response to Mine Water Challenges. International Mine Water Conference, August 2014 Xuzhou China. Editors, Sui, Sun \& Wang (Eds). 2014 China University of Mining andTechnology Press, Xuzhou, ISBN: 978-7-5646-2437-8. Pp374-378.

[32] E. Fosso-Kankeu, F. Waanders. 2014. Metal Ions Adsorption Affinity of Clay Materials from the North West Province of South Africa. An Interdisciplinary Response to Mine Water Challenges. International Mine Water Conference, August 2014 Xuzhou China. Editors, Sui, Sun \& Wang (Eds). 2014 China University of Mining andTechnology Press, Xuzhou, ISBN: 978-7-5646-2437-8. Pp374-378.

[33] Fosso-Kankeu E, Waanders F, Reitz M. 2014. Selective adsorption of heavy and light metals by natural zeolites. $6^{\text {th }}$ International Conference on Green Technology, Renewable Energy and Environmental Engineering (ICGTREEE'2014). 27-28 November 2014, Cape TownSouth Africa. (Award Winning Paper). Editors: Muzenda E. and Sandhu S. ISBN: 978-93-84468-08-8. Pp 271-274.

[34] Fosso-Kankeu Elvis, Van der Berg Charl M., Frans B. Waanders. 2014. Physico-chemical activation of South African bentonite clay and impact on metal adsorption capacity. $6^{\text {th }}$ International Conference on Green Technology, Renewable Energy and Environmental Engineering (ICGTREEE'2014). 27-28 November 2014, Cape Town-South Africa. Editors: Muzenda E. and Sandhu S. ISBN: 978-93-84468-08-8. Pp 247-252.

[35] Distantina, S., Rochmandi, Fahrurrozi, M. \& Wiratni, 2013. Preparation and Characterization of Glutaraldehyde Crosslinked Kappa Carrageenan Hydrogel. Engineering Journal, 17(3), pp. 57-66.

[36] El-Sherif, H. \& El-Masry, M., 2011. Superabsorbent nanocomposite hydrogels based on intercalation of chitosan into activated bentonite. Polymer bulletin, 66(6), pp. 721-734.

[37] Okeola, F.O. \& Odebunmi, E.O. 2010. Freundlich and Langmuir isotherms parameters for adsorption of methylene blue by activated carbon derived from agrowastes. Advances in natural and applied sciences, 4: 281-288.

[38] Theivarasu, C., Mylsamy, S. \& Sivakumar, N. 2011. Kinetics, isotherms and thermodynamics studies of adsorption of congo red from aqueous solution onto cocoa shell activated carbon. Research journal of chemistry and environment, 15(2011):34-38.

[39] Fosso-Kankeu E, Mittal H, Mishra SB, Mishra AK. 2015. Gum ghatti and acrylic acid based biodegradable hydrogels for the effective adsorption of cationic dyes. Journal of Industrial and Engineering Chemistry. 22: 171-178.

The corresponding author is currently an Associate Professor in the School of Chemical and Minerals Engineering at the North-West University (Potchefstroom). He is an NRF rated researcher who has published journal articles, book chapters and book.

Prof Elvis Fosso-Kankeu has been the recipient of several merit awards. 